\title{
Pleiotropic effects and pharmacological properties of penehyclidine hydrochloride
}

This article was published in the following Dove Press journal:

Drug Design, Development and Therapy

\section{Yaguang Wang \\ Yafen Gao \\ Jun Ma}

Department of Anesthesiology, Beijing Anzhen Hospital, Capital Medical University-Beijing Institute of Heart Lung and Blood Vessel Diseases, Beijing, People's Republic of China
Correspondence: Jun Ma

Department of Anesthesiology, Beijing Anzhen Hospital, Capital Medical University, 2 Anzhen Road, Chaoyang, Beijing 100029, People's Republic of China

Tel +86 I33 70I0 357|

Email18710168703@163.com
Background: Penehyclidine hydrochloride (PHC) is an anticholinergic drug manufactured in China. It is used widely in clinics as a reversal agent in cases of organic phosphorus poisoning and as a preanesthetic medication. Compared with other anticholinergic agents, PHC confers substantial advantages. Here, in this review, we focus on its important clinical effects for organic phosphorus poisoning, preanesthetic medication, and the protective effects on certain visceral organs.

Materials and methods: Our bibliographic sources include the PubMed and China National Knowledge Infrastructure (CNKI) databases, updated in March 2018. To assess the data in detail, we used the search terms "penehyclidine hydrochloride," "preanesthetic medication," and "organic phosphorus." Papers were restricted to those published in the English and Chinese languages, and to "paper" and "review" as the document type.

Results: PHC can effectively antagonize the symptoms of central and peripheral poisoning caused by organophosphorus poisoning. As a preanesthetic medication, it can not only effectively reduce mucus secretion and vascular infiltration but can also relax airway smooth muscles, dilate bronchioles in pulmonary conditions such as bronchiectasis, and increase pulmonary dynamic compliance. It can also prevent reflexive actions of the vagus nerve caused by excessive acetylcholine release such as abnormal airway contraction. Furthermore, it can strengthen sedation, bidirectionally regulate heart rate, and effectively inhibit respiratory secretions. In recent studies, PHC was shown to also have protective effects on various organs, such as the heart, lungs, brain, kidneys, intestines, and liver.

Conclusion: PHC has beneficial pharmacological properties used in the treatment of organophosphorus poisoning and as a preanesthetic medication for its few side effects. It also has protective effects on multiple organs, suggesting that PHC has extensive clinical application value which is worth further research. This review should be of help to those intending to research these topics further.

Keywords: penehyclidine hydrochloride, preanesthetic medication, organic phosphorus, organ protection, ischemia-reperfusion, septic shock, central sedation

\section{Introduction}

Penehyclidine hydrochloride (PHC) (Figure 1) or 3-(2'-phenyl-2'-cyclopentyl$2^{\prime}$-hydroxyl-ethoxy) quinuclidine is a new anticholinergic drug from scopolamine developed by the Chinese Academy of Military Sciences that binds to both $\mathrm{M}$ and $\mathrm{N}$ cholinergic receptors. The molecular formula of $\mathrm{PHC}$ is $\mathrm{C}_{20} \mathrm{H}_{29} \mathrm{NO}_{2} \cdot \mathrm{HCl}$, and the formula weight is 351.92. Because it can pass through the blood-brain barrier, PHC has potent peripheral and central anticholinergic effects. ${ }^{1}$

Currently, PHC is widely used in clinics in China as a reversal agent in cases of organophosphorus poisoning and before surgical operations. Basic and clinical 


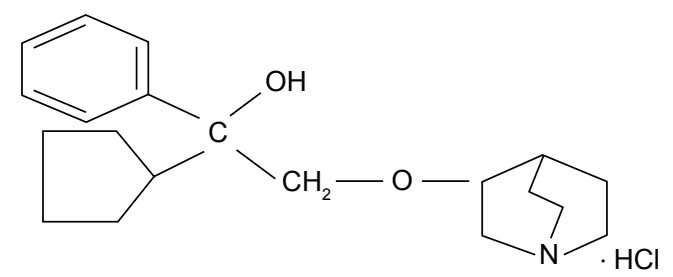

Figure I The chemical structure of PHC.

Abbreviation: $\mathrm{PHC}$, penehyclidine hydrochloride.

studies performed in our laboratory and at other institutions show that the main advantage of PHC is that it has no muscarinic 2 receptor-associated cardiovascular side effects that increase the heart rate. ${ }^{2}$ PHC can selectively act on muscarinic 1, 3, and nicotine receptors, as shown in Table 1. Compared with atropine, scopolamine, and other anticholinergic drugs, PHC has a great advantage in pharmacology, as shown in Table $2 .{ }^{3}$ It can also inhibit lipid peroxidation, attenuate the release of lysosomes, and depress microvascular permeability. ${ }^{4}$ Furthermore, $\mathrm{PHC}$ has a significant protective effect on various organs, such as the heart, ${ }^{5}$ lungs, ${ }^{4}$ and brain through antioxidant, antiapoptotic, and anti-inflammatory properties. It also plays an important role in the treatment of septic shock. ${ }^{6}$ Here, we present an in-depth survey of the available scientific information on the potential clinical roles of PHC. Because our aim was to identify state of the art information, our literature search was restricted to research on PHC.

\section{Materials and methods}

Two investigators (Yaguang Wang and Yafen Gao) reviewed publications based on their titles and abstracts. The flowchart of the search is shown in Figure 2. Exclusion criteria: 1) Duplicate report. 2) There are defects in research and

Table I Actions of PHC on muscarinic and nicotinic receptors

\begin{tabular}{l|l|l}
\hline Effective apparatus & $\begin{array}{l}\text { Blocked } \\
\text { receptor }\end{array}$ & Effect \\
\hline Nervus centralis & NI & Restrain \\
Skeletal muscle ganglion & N2 & Restrain \\
Coronary artery & Relaxation \\
Cutaneous mucosal vessels & M & Relaxation \\
Iridis sphincter & M3 & Relaxation \\
Detrusor & M3 & Relaxation \\
Bronchial smooth muscles & M3 & Relaxation \\
Gastric smooth muscles & M3 & Relaxation \\
Small intestinal smooth muscles & M3 & Relaxation \\
Sweat gland & M3 & Hyposecretion \\
Salivary glands & M3 & Hyposecretion \\
Bronchial gland & M3 & Hyposecretion \\
\hline
\end{tabular}

Abbreviation: PHC, penehyclidine hydrochloride. design or poor quality of the paper. 3) Incomplete data or unclear outcome. 4) Incorrect statistical method and cannot be corrected. The metrology data cannot provide the mean and SD.

\section{Results and discussion Pharmacokinetics of PHC}

After intramuscular injection of $1 \mathrm{mg}$ of PHC in healthy adults, it can be detected in the blood after 2 minutes. The peak blood concentration time is $\sim 34$ minutes, and the peak concentration is $\sim 13.20 \mu \mathrm{g} / \mathrm{L} .{ }^{1}$ Animal experiments show that after intramuscular injection, PHC is widely distributed in the tissues of the whole body. Submandibular glands were found to have the highest concentration, followed by the lungs, spleen, intestines, heart, kidneys, and muscles. PHC is mainly excreted by urine and feces. The total 24-hour excretion is $94.17 \%$ of the dosage. ${ }^{1}$ Dizziness, retention of urine, delirium, and high body temperature can occur in large doses in adults. However, after withdrawal, the symptoms abate spontaneously, as shown in Table 3. A brief description of the studies included in the review, pharmacological actions evaluated in the studies, and the overall results are shown in Table 4.

Acute organophosphorus pesticide poisoning is a common critical illness in emergency departments. How can we improve the cure rate of this severe poisoning and reduce mortality associated with organophosphate poisoning? The traditional treatment method is mainly to use chlorodipine and atropine together. ${ }^{7,8}$

Patients' sensitivity to atropine can differ. The therapeutic dose of atropine treatment is very close to the poisonous dose. In clinical practice, it is generally difficult for doctors to accurately master the usage and dosage of atropine and it is easy to under or overdose. In addition, atropine only works well against peripheral $\mathrm{M}$ cholinergic receptors; while its central anticholinergic effect is very limited. Thus, atropine cannot antagonize and alleviate the central cholinergic and $\mathrm{N}$ cholinergic receptors involved in organophosphate poisoning. ${ }^{9}$ The causes of death and deadly complications of poisoned patients are often related to the central toxicity of organophosphate. In addition, atropine has significant cardiovascular and other side effects. In cases of severe organophosphate poisoning in elderly patients and patients with underlying diseases, serious deadly complications can arise by using atropine. ${ }^{10}$

In these populations, it is beneficial that PHC has no muscarinic 2 receptor-associated cardiovascular side effects. ${ }^{2}$ By using PHC instead of atropine, clinicians can avoid unwanted increases in the heart rate. Therefore, the traditional 
Table 2 The comparison between the advantages and disadvantages of PHC with previous anticholinergic drugs

\begin{tabular}{|c|c|c|}
\hline Name & Medicine & \\
\hline \multirow{4}{*}{$\begin{array}{l}\text { Half-life } \\
\text { period }\end{array}$} & $\mathrm{PHC}$ & 10.35 hours \\
\hline & Atropine & 3.7-4.3 hours \\
\hline & Ranunculum & 40 minutes \\
\hline & Scopolamine & 1.35 hours \\
\hline \multirow[t]{4}{*}{ Advantage } & $\mathrm{PHC}$ & $\begin{array}{l}\text { It has strong, comprehensive central and peripheral anticholine action, persistent inhibition of glandular } \\
\text { secretion, strong anticholine effect, and central sedation and protection of heart rate, bidirectional regulation } \\
\text { mechanism, small side effects, improved microcirculation, and multi-organ protection }\end{array}$ \\
\hline & Atropine & $\begin{array}{l}\text { Relieving spasm of smooth muscles, relieving vasospasm of small vessels, improving microcirculation, inhibiting } \\
\text { glandular secretion, relieving the inhibition of vagus nerve on the heart, and exciting the respiratory center }\end{array}$ \\
\hline & Ranunculum & $\begin{array}{l}\text { Long-term application has no accumulative effect, low toxicity, and no damage to liver and kidney parenchyma } \\
\text { organs }\end{array}$ \\
\hline & Scopolamine & $\begin{array}{l}\text { The peripheral effect is strong, can selectively relieve gastrointestinal tract, biliary tract, urinary tract smooth } \\
\text { muscle spasms, improve microcirculation, stimulate the respiratory center, dilate the bronchus, and reduce } \\
\text { respiratory tract secretion }\end{array}$ \\
\hline \multirow[t]{4}{*}{ Disadvantage } & $\mathrm{PHC}$ & $\begin{array}{l}\text { The dosage is often accompanied by dry mouth, red face, and dry skin. If dosage is too large, it can lead to } \\
\text { dizziness, urine retention, delirium, rise in body temperature, and so on }\end{array}$ \\
\hline & Atropine & $\begin{array}{l}\text { It has no obvious effect on skeletal muscle tremor caused by organophosphorus poisoning, and should not be } \\
\text { used in patients with bronchial asthma. Infants and children are very sensitive to its toxic reactions. It has the } \\
\text { danger of sudden rise of body temperature due to the blocking of sweat glands }\end{array}$ \\
\hline & Ranunculum & $\begin{array}{l}\text { The inhibition of salivary glands and pupillary dilation is weak and cannot pass through the blood-brain } \\
\text { barrier, and the central role is weak }\end{array}$ \\
\hline & Scopolamine & $\begin{array}{l}\text { Strong mydriasis, inhibition of glandular secretion and cerebral cortex, high toxicity, drug overdose can cause } \\
\text { delirium, agitation, even convulsion, respiratory failure, and even death }\end{array}$ \\
\hline
\end{tabular}

Abbreviation: PHC, penehyclidine hydrochloride.

patient monitoring standard of "atropinization" for observation of curative effects needs to be adjusted. Clinically, the anticholinergic effects of PHC are often judged through symptoms such as dry mouth, xerosis cutis, diminished or dissipated pulmonary rales, and diminished or disappeared sweating. ${ }^{10}$

For rapid absorption of $\mathrm{PHC}$ in the body, an intramuscular injection of the appropriate dose can quickly achieve similar

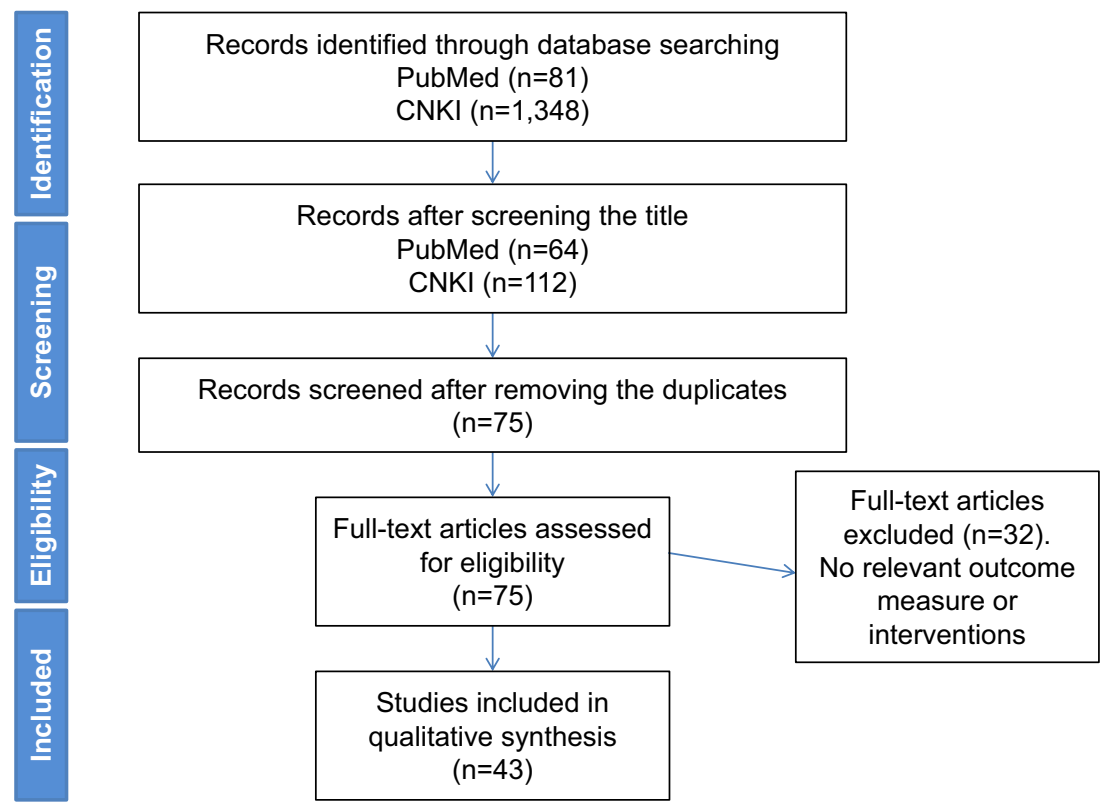

Figure 2 Flow diagram for studies included in this review.

Abbreviation: CNKI, China National Knowledge Infrastructure. 
Table 3 The side effects associated with PHC

\begin{tabular}{l|l|l}
\hline Critical organ & Dosage & Side effect \\
\hline $\begin{array}{l}\text { Skin } \\
\text { Salivary gland } \\
\text { Bronchial gland }\end{array}$ & Therapeutic & Flushing and drying \\
& Therapeutic & Dry \\
Inhibition of glandular secretion (careful use of severe \\
respiratory tract infections with low sputum) \\
Temperature & Bherapeutic & Blurred vision (not allowed for glaucoma) \\
Urinary system & Large & Fervescence \\
Nervous system & Large & Urinary retention (careful use of prostatic hypertrophy) \\
\end{tabular}

Abbreviation: PHC, penehyclidine hydrochloride.

"atropinization" effects in clinical practice. As PHC is a longacting agent, it can be administered in 6-12-hour intervals for maintenance. ${ }^{1}$ It is easier to control and master the usage and dosage of PHC than atropine. It can also reduce the workload of medical staff and may also have a role in preventing the intermediate syndrome following organophosphate poisoning.

Because PHC will suppress symptoms by restoring the activity of cholinesterase without treating the condition, it is

Table 4 The brief description of the studies included in the review

\begin{tabular}{|c|c|c|}
\hline Application & Mechanism of action & Effect \\
\hline $\begin{array}{l}\text { Rescue of organophosphorus } \\
\text { poisoning }\end{array}$ & $\begin{array}{l}\text { Anti-acetylcholine and nicotinic effects of } \\
\text { acetylcholine }\end{array}$ & $\begin{array}{l}\text { Antagonistic symptoms of central and peripheral } \\
\text { alkaline-like poisoning, and maintenance of } \\
\text { atropinization in late stage of poisoning or aging of } \\
\text { cholinesterase }\end{array}$ \\
\hline Preanesthetic medication & $\begin{array}{l}\text { Blocking } M_{1} \text { and } M_{3} \text { receptors, and not acting on } \\
M_{2} \text { receptors }\end{array}$ & $\begin{array}{l}\text { Sedation, inhibition of glandular secretion, inhibition } \\
\text { of vagal reflex, and no increase in heart rate }\end{array}$ \\
\hline COPD & Attenuate TLR & As a potentially promising candidate agent \\
\hline ALI & $\begin{array}{l}\text { Inhibition of inflammatory response by inhibition of } \\
\text { TLR4 receptor }\end{array}$ & $\begin{array}{l}\text { Improvement of arterial oxygen pressure in } \\
\text { patients }\end{array}$ \\
\hline Sepsis (mice or rat) & $\begin{array}{l}\text { Antioxidants reduce lung vascular endothelial damage } \\
\text { and inhibit inflammatory pathways such as p } 38 \\
\text { MAPK/NF- } \mathrm{KB} \text { signaling pathways to inhibit } \\
\text { inflammatory response }\end{array}$ & Has a protective effect \\
\hline Traumatic lung injury (rat) & $\begin{array}{l}\text { Inhibition of the TLR4 pathway and upregulation of } \\
\text { the expression of } \mathrm{Bcl}-2 / \mathrm{Bax}\end{array}$ & Has a protective effect \\
\hline Heart I/R injury (rat) & $\begin{array}{l}\text { Anti-oxidation, anti-inflammation through NF- } \mathrm{KB} \text { and } \\
\text { mitochondria-induced intrinsic pathways, improve } \\
\text { the imbalance of mitochondrial dynamics to } \\
\text { anti-apoptosis, and VDACl is the handle channel }\end{array}$ & $\begin{array}{l}\text { Has a protective effect and exert long-term cardio } \\
\text { protection }\end{array}$ \\
\hline $\begin{array}{l}\text { Patient suffering from respiratory or } \\
\text { cardiac arrest }\end{array}$ & $\begin{array}{l}\text { Inhibition of calcium influx and effectively improves } \\
\text { cell tolerance to ischemia and hypoxia }\end{array}$ & $\begin{array}{l}\text { Improves cerebral perfusion pressure, reduce } \\
\text { cerebral edema, and improve neurological function }\end{array}$ \\
\hline Cerebral I/R (rat) & $\begin{array}{l}\text { Altered the expressions of } \mathrm{Bcl}-2 \text { and caspase- } 3 \text {, inhibit } \\
\text { oxidative stress, open mPTP, glutamate release, } \\
\text { excitotoxicity, and } \mathrm{N} \text {-methyl-D-aspartate receptor I } \\
\text { expression. The activation of MitoKATP is critical }\end{array}$ & Protects against $I / R$ injury in the brain \\
\hline Central sedation & Block the central $M_{1}$ receptor & Has a certain central sedative effect \\
\hline Renal I/R injury (rat) & $\begin{array}{l}\text { Attenuate oxidative stress, the inflammatory } \\
\text { response, and apoptosis }\end{array}$ & $\begin{array}{l}\text { Represents a novel practical strategy for the } \\
\text { treatment of renal I/R injury }\end{array}$ \\
\hline RM-induced AKI (rat) & $\begin{array}{l}\text { Promote the } \mathrm{Nrf2} / \mathrm{HO}-\mathrm{I} \text { pathway, alleviate oxidative } \\
\text { stress, and renal cell apoptosis }\end{array}$ & PHC pretreatment ameliorates RM-induced AKI \\
\hline $\begin{array}{l}\text { Small intestinal mucosal injury } \\
\text { induced by lower limb I/R injury (rat) }\end{array}$ & $\begin{array}{l}\text { Inhibit oxygen free radicals and inflammatory } \\
\text { cytokines }\end{array}$ & Has a protective effect \\
\hline $\begin{array}{l}\text { Patients undergoing cardiopulmonary } \\
\text { bypass }\end{array}$ & $\begin{array}{l}\text { Improve intestinal microcirculation and depress the } \\
\text { stress response }\end{array}$ & Attenuates endotoxemia \\
\hline Septic shock & $\begin{array}{l}\text { Relieve small vasospasms, reduce peripheral vascular } \\
\text { resistance, improve microcirculation, and increase } \\
\text { tissue perfusion }\end{array}$ & Has a protective effect \\
\hline
\end{tabular}

Note: Application of $\mathrm{PHC}$ in the treatment of organophosphorus pesticide poisoning.

Abbreviations: AKI, acute kidney injury; ALI, acute lung injury; Bax, BCL (B Cell Lymphoma)-Associated X; Bcl-2, B-cell lymphoma-2; I/R, ischemia/reperfusion; MAPK, mitogen-activation protein kinase; MiotoKATP, mitochondrial ATP-dependent K+ channel; mPTP, mitochondrial permeability transition pore; NF-KB, nuclear transcription factor kappa-B; PHC, penehyclidine hydrochloride; VDACI, voltage-dependent anion channel I; TLR4, toll-like receptor-4; RM, rhabdomyolysis. 
still crucial to use cholinesterase reactivators such as chlorodiphosphate when treating patients with organophosphorus poisoning, especially those who are severely poisoned. The general principle is to give enough of a PHC-load together with anticholinergic drugs, both at an early stage and upon repeat dosing. ${ }^{10}$

The research by Wenjie et al showed that PHC could be superior to atropine in treating severe organophosphorus poisoning increasing the total cure rate, decreasing the total mortality rate, and decreasing the incidence rate of severe complications. ${ }^{10}$ This finding was confirmed by Cui et al. In the study of swine, the PHC group showed a mild impairment in pathology, fewer apoptotic cells, and a low impact on cardiac function when compared with the atropine group for dichlorvos-induced acute lung injury (ALI). ${ }^{11}$ More restrictive recommendations were presented by Yu and Zheng, who suggested the curative effect of PHC sequential to atropine was more significant. ${ }^{12}$

\section{Application of PHC before anesthesia}

Preoperative application of anticholinergic drugs can reduce the fear and tension of patients, reduce respiratory secretions, and inhibit the vagus nerve reflex. Atropine is widely used clinically prior to anesthesia, but its main deficiency is that it has no selectivity when acting on $\mathrm{M}$ choline receptors, potentially increasing blood pressure and heart rate, and even leading to arrhythmia. The effect of scopolamine on heart rate is lower than atropine, but its inhibition of glandular secretion is also weak.

PHC is a new type of selective anticholinergic drug, which has a powerful and lasting effect on inhibiting glandular secretion, as well as on central sedation and prevention of vagus reflex effects. ${ }^{1}$ The results showed that the affinity of PHC to the M receptor subtype was obvious; that is, it mainly acted on $M_{1}$ and $M_{3}$ subtype receptors but weakly affected $M_{2}$ subtype receptors. ${ }^{2}$ Because there is no obvious selectivity for the $\mathrm{M}_{2}$ receptors in the heart and in presynaptic neuron membranes, its effects on heart rate are mainly regulated by central feedback. The clinical manifestation of PHC is that the heart rate is bidirectionally regulated to keep it in a normal physiological state. PHC can not only effectively inhibit respiratory secretions and relieve smooth muscle spasms but also maintains the stability of the cardiovascular system without increasing myocardial oxygen consumption or the stress response. ${ }^{2}$ Used before surgical operations, PHC enhances the depth of anesthetic sedation and inhibits respiratory secretions effectively for a long time, has a weak effect on body temperature, and has no obvious effect on presynaptic neuron membrane $M_{2}$ receptors.
PHC maintains normal neurotransmitter regulation; thus, urinary retention and intestinal paralysis can be avoided effectively, ensuring rapid postoperative recovery. It can be used as the first choice for the elderly, children, and patients with cardiovascular disease, hyperthyroidism, and fever.

A study by Liu et al demonstrated that $0.5 \mathrm{mg}$ of PHC stabilizes potential fluctuations in the heart rate variability without significantly altering the autonomic nerve modulation of heart rate. $\mathrm{PHC}$ at a dose of $1.0 \mathrm{mg}$ may be superior to $0.5 \mathrm{mg} \mathrm{PHC}$ in maintaining a stable heart rate, and reduces the incidence of bradycardia; however, the higher dose is less effective at maintaining sympathetic and parasympathetic balance. ${ }^{13}$ Additionally, a study by Wang et al demonstrated that $\mathrm{PHC}$ reduced the incidence of intraoperative awareness in patients undergoing breast cancer surgery during general anesthesia. ${ }^{14}$

\section{Application of $\mathrm{PHC}$ in respiratory diseases}

ALI and acute respiratory distress syndrome can be caused by internal or external pathogenic factors. Currently, the initial factor in acute pulmonary microcirculation disorders is the release of a large amount of acetylcholine in the body, which causes continual pulmonary microvasospasms. At the same time, the density of cholinergic receptors is upregulated, causing increased tension of vascular and airway smooth muscles, thus increasing airway resistance and decreasing airway responsiveness.

There are 5 M-type receptors in human lung tissue: $M_{1}, M_{2}, M_{3}, M_{4}$, and $M_{5}$. Currently, strong evidence for a functional role only exists for $\mathrm{M}_{1}, \mathrm{M}_{2}$, and $\mathrm{M}_{3}$ receptors. ${ }^{15}$ $M_{1}$ receptors are distributed on the postsynaptic membranes of parasympathetic ganglia. Vagus nerve stimulation (VNS) causes the $\mathrm{M}_{1}$ receptor to promote cholinergic neurotransmission, thus inducing bronchoconstriction. ${ }^{15,16} \mathrm{M}_{2}$ receptors are distributed in parasympathetic postganglionic nerve endings. These neuronal $\mathrm{M}_{2}$ receptors are activated by acetylcholine to inhibit further acetylcholine release in a feedback mechanism that limits vagally induced bronchoconstriction and mucus secretion in healthy animals and humans. ${ }^{15,17} \mathrm{M}_{3}$ receptors are mainly distributed in respiratory smooth muscles, submucosal glands, and other effector organs, which can mediate bronchoconstriction and cause submucosal glands to secrete mucus. $M_{3}$ receptors are responsible for both vagal and exogenous acetylcholine-induced mucin secretions. ${ }^{15,18,19}$ Most lung tissues express more than one muscarinic receptor subtype, but the function of one muscarinic subtype is often dominant. Where the functions of additional muscarinic receptor subtypes are known, they either inhibit or supplement the dominant receptor's function. ${ }^{20}$ 
The application of PHC can effectively antagonize cholinergic effects, relieve pulmonary microvasospasms, reduce glandular secretions, relieve bronchial smooth muscle spasms, relieve airway resistance and increase respiratory flow via anticholinergic effects.

The results of basic and clinical studies suggest that PHC is effective in the prevention and treatment of ALI of various causes. Xiao et al investigated $\mathrm{PHC}$ as a potentially promising candidate agent in the treatment of COPD in the future because of its ability to attenuate toll-like receptors. ${ }^{21}$ This finding was confirmed by Li et al, based on a study in patients with ALI, which found that PHC improves arterial oxygen pressure and restrains the inflammatory cytokines downstream of the TLR4 signaling pathway, as shown in Figure $3 .^{22}$ PHC can also have protective effects in traumatic lung injury via the inhibition of the TLR4 pathway. Moreover the effects of $\mathrm{PHC}$ on regulating the expressions of BCL (B Cell Lymphoma)-Associated X (Bax) and B-cell lymphoma-2 (Bcl-2) may play an important role in the inhibition of apoptosis in lung tissue cells. ${ }^{23,24}$

PHC has a great advantage in the treatment of sepsis regardless of being induced by cecal ligation and puncture or lipopolysaccharide. ${ }^{4,25}$ The possible mechanisms are anti-oxidation by attenuating ROS injury, upregulating $\beta$-arrestin-1 expression against pulmonary microvascular endothelial cell injury, ${ }^{26}$ and anti-inflammation through the inhibition of NF- $\mathrm{KB}$ activation via inhibition of the $\mathrm{p} 38$ mitogenactivation protein kinase (MAPK) and ERK signaling pathways (Figure 3). The findings by Wu et al indicated that different doses of PHC, especially, a medium dose could prevent LPS-induced ALI in rats. The protection of pharmacologic post-conditioning with PHC is limited by a "ceiling effect". ${ }^{27}$ Both VNS and treatment with acetylcholine or pseudocholinesterase are capable of suppressing LPS-induced systemic inflammatory response syndrome, as well decreasing release of tumor necrosis factor (TNF)- $\alpha$, interleukin (IL)-1 $\beta$, and IL- 6 , and has been termed as "cholinergic anti-inflammatory pathway". ${ }^{28}$ Therefore, Wang et al hypothesized that PHC, an anticholinergic drug similar to atropine, suppresses the cholinergic anti-inflammatory pathway and abolishes pulmonary protective effects at higher concentrations. Future studies are needed to confirm this hypothesis. ${ }^{29}$

Animal and clinical trials have shown that PHC has protective effects on ALI caused from various causes due to its anti-inflammatory, anti-oxidation and anti-apoptosis effects. Unfortunately, there is no study on the role of PHC in ischemia-reperfusion injuries in humans.

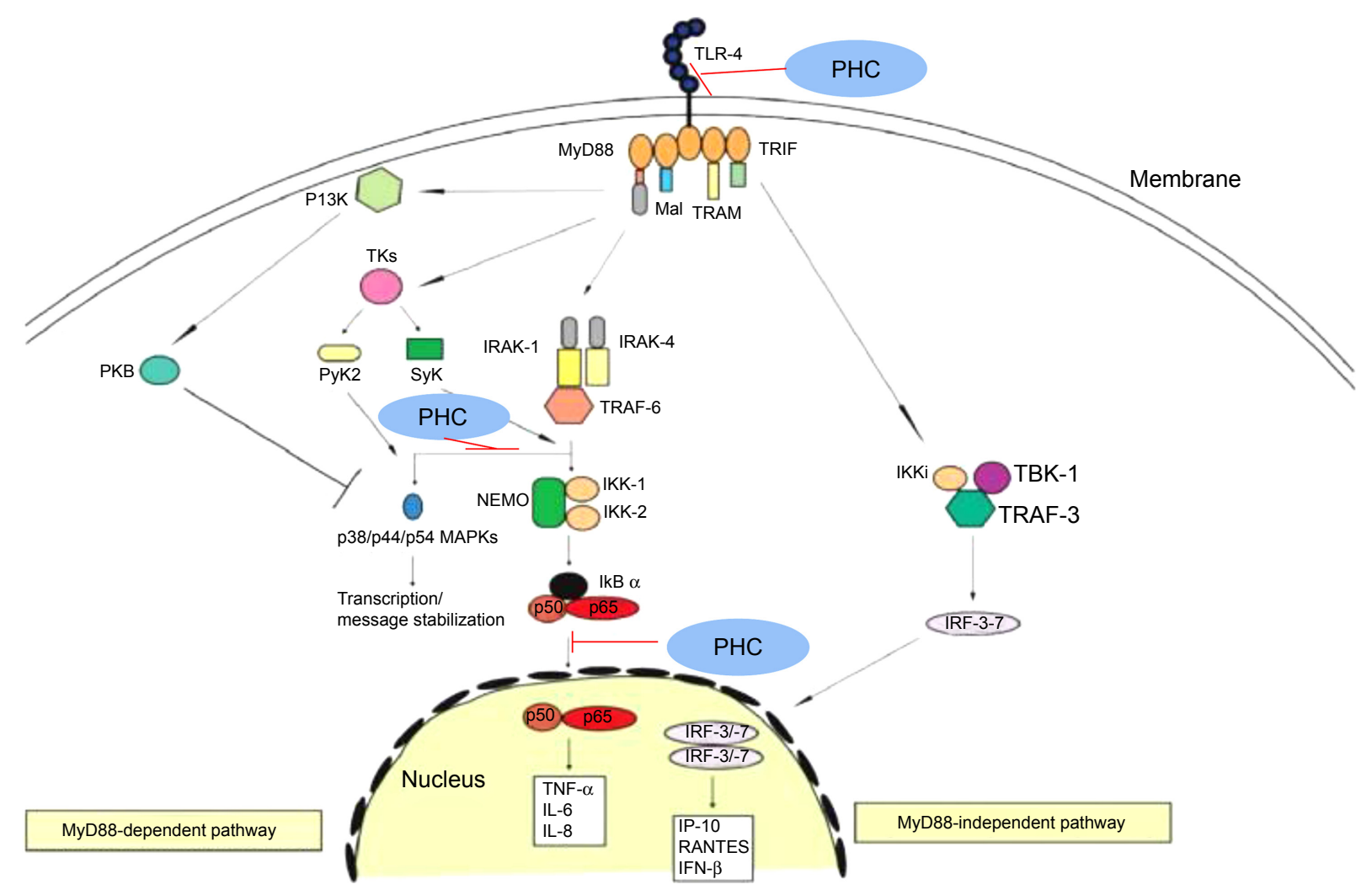

Figure 3 The mechanism of antiapoptotic effects of PHC in ALI.

Abbreviations: ALI, acute lung injury; IL, interleukin; INF, interferon; IP-I0, interferon-gamma inducible protein I0; Mal, MyD88-adapter-like; MAPKs, mitogen-activation protein kinases; MyD88, myeloid differentiation factor 88; NF- $\mathrm{KB}$, nuclear transcription factor kappa-B; PHC, penehyclidine hydrochloride; TLR-4, toll-like receptor 4; TNF, tumor necrosis factor; TRIF, TIR-domain-containing adapter-inducing interferon- $\beta$. 


\section{The protective effects of PHC on heart ischemia-reperfusion}

At present, myocardial ischemia-reperfusion studies with PHC are in basic animal research, investigating antiinflammatory and anti-apoptosis mechanisms, especially, through mitochondria-induced intrinsic pathways (Figure 4) to alleviate myocardial ischemia-reperfusion injuries. The clinical application of myocardial protection drugs in the future has great potential and needs further study.

The anti-oxidation property of PHC in heart ischemiareperfusion has been demonstrated through reducing total NO levels, ROS production, and Malondialdehyde (MDA) content by Lin et al. ${ }^{5}$ The results were confirmed by Tan et al, who also suggested PHC protects cardiomyocytes by ameliorating $\mathrm{Ca}^{2+}$ overload. ${ }^{30}$

PHC significantly reduces the release of inflammatory mediators such as TNF- $\alpha$, IL- $1 \beta$, IL-6, PGE 2 , and COX-2 in vitro through the inhibition of nuclear transcription factor kappa-B (NF-KB), and the activation of inhibitor of NF- $\kappa$

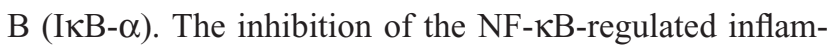
matory response pathway is the probable anti-inflammatory mechanism of PHC. Moreover, PHC also exerted long-term cardio-protection in a rat model of $\mathrm{I} / \mathrm{R}$ injury. ${ }^{5}$
The modulation of the mitochondrial apoptosis pathway is critical for the anti-apoptosis effect of PHC. Its antiapoptotic mechanism consists of suppression of Bax expression, activation of Bcl-2, promotion of the recovery of mitochondrial outer membrane permeabilization, and inhibition of voltagedependent anion channel 1 (VDAC1), cytosol cytochrome c (cyt-c), and cleaved caspase- 3 in myocardial I/R..$^{30,31}$ This finding was confirmed by Lin et al, based on a study in $\mathrm{H} 9 \mathrm{c} 2$ cells after anoxia/reoxygenation (A/R). Additionally, VDAC1 may be a bona fide target of PHC for protection against myocardial I/R injury. ${ }^{32}$

PHC preconditioning can also improve the imbalance of mitochondrial dynamics to alleviate the cellular apoptotic rate. A study by Yang et al demonstrated that PHC protected the myocardium from I/R injury by improving mitochondrial dynamics and apoptosis through inhibition of dynaminrelated peptide1 expression and promoting the expression of mitofusins 1 and $2 .^{33}$

\section{The protective effects of $\mathrm{PHC}$ on cerebral ischemia/reperfusion ( $\mathrm{Cl} / \mathrm{R})$}

$\mathrm{CI} / \mathrm{R}$ leads to disability and death worldwide. $\mathrm{CI} / \mathrm{R}$ injury is related to oxygen free radical formation, calcium overload,

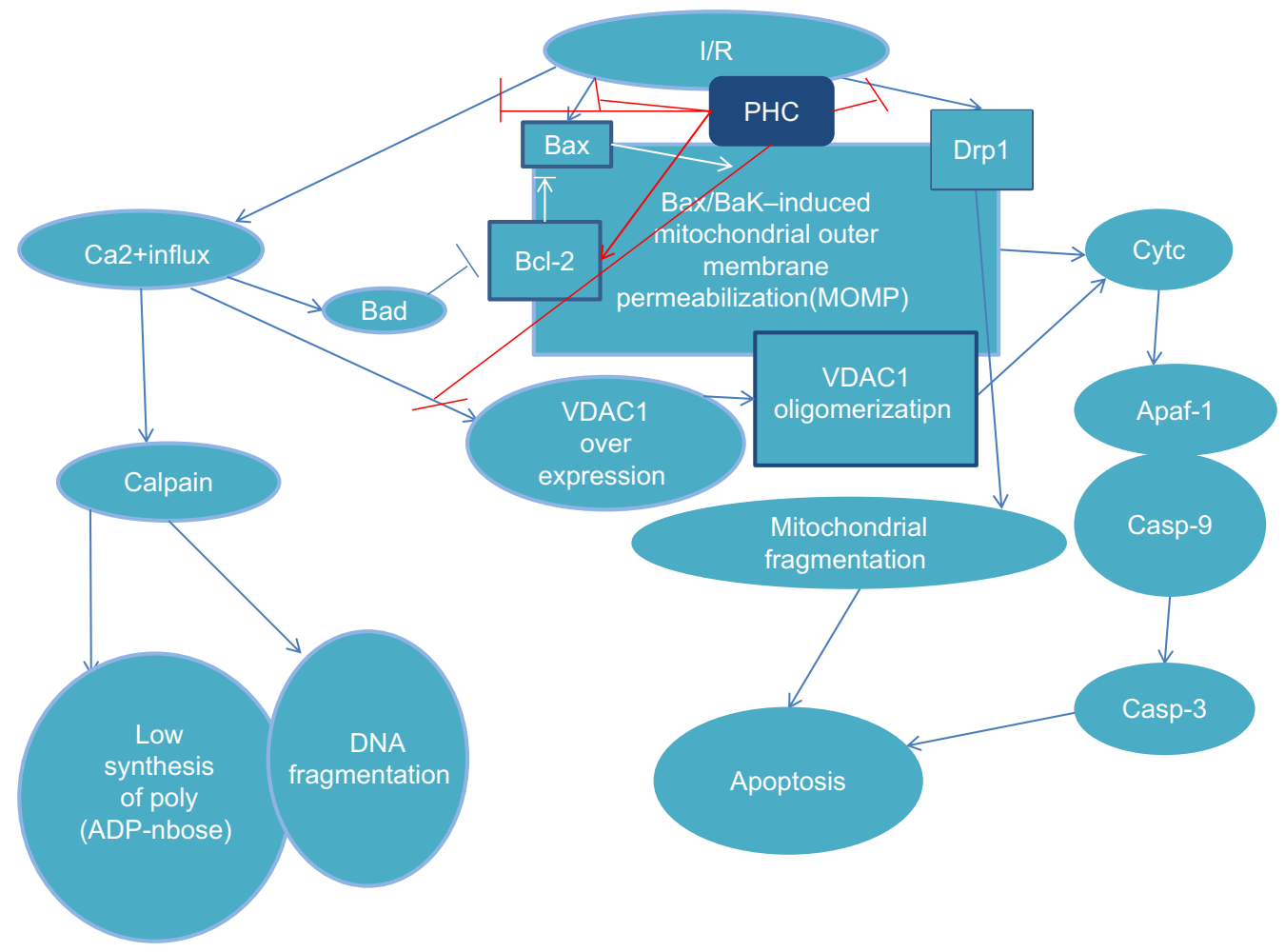

Figure 4 The mechanism of antiapoptotic effect of $\mathrm{PHC}$ in heart I/R injury.

Abbreviations: Bax, BCL (B Cell Lymphoma)-Associated X; Bcl-2, B-cell lymphoma-2; Casp-3, caspase-3; Casp-9, caspase-9; cyt-c, cytosol cytochrome c; DrpI, dynamin-related peptide I; I/R, ischemia/reperfusion; MOMP, mitochondrial outer membrane permeabilization; PHC, penehyclidine hydrochloride; VDACI, voltage-dependent anion channel I; $\mathrm{BAD}, \mathrm{Bcl}-2 / \mathrm{Bcl}-\mathrm{X}(\mathrm{L})$-antagonist, causing cell death; ApafI, Apoptotic protease activating factor I. 
neutrophil infiltration, and endothelial cell damage. The anti-inflammatory, anti-oxidation, and antiapoptotic effects of PHC on $\mathrm{CI} / \mathrm{R}$ injury are similar to the mechanisms in lung and heart. However, there are also some interesting new findings.

$\mathrm{N}$-methyl-D-aspartate receptors are ligand-gated $\mathrm{Ca}^{2+}$ channels and are highly permeable to $\mathrm{Ca}^{2+}$, which plays an essential role in excitotoxicity. Excessive intracellular $\mathrm{Ca}^{2+}$ can activate phospholipase $\mathrm{A}$, and biofilm phospholipid degradation can generate arachidonic acid, prostaglandins, thromboxanes, and leukotrienes, resulting in an inflammatory reaction and the generation of oxygen free radicals causing cell damage. A study by $\mathrm{Yu}$ and Wang demonstrated PHC protected hippocampal neurons from injury by inhibiting excitotoxicity and N-methyl-D-aspartate receptor overexpression following focal $\mathrm{CI} / \mathrm{R}$ injury. ${ }^{34}$

This finding was confirmed by Shang et al, who suggested that the protective mechanisms of PHC are involved in inhibiting glutamate release and N-methyl-D-aspartate receptor 1 expression. ${ }^{35}$ MAPKs are important signaling components that link extracellular stimuli to a multitude of intracellular responses that affect cell growth, differentiation, survival, and metabolic regulation. Three major MAPK classes have been reported: ERK1/2, p38 MAPK, and c-Jun N-terminal kinase (JNK); and their activation plays a central role in stress-induced apoptosis. Cerebral I/R injury induced a significant increase in the expression of phosphorylated-JNK (p-JNK), phosphorylated-p38MAPK (p-p38MAPK), and
phosphorylated-c-Jun (p-c-Jun), which were downregulated by $\mathrm{PHC}$ treatment, suggesting that the neuroprotective effect of PHC is mediated by $\mathrm{JNK} / \mathrm{p} 38$ MAPK signaling pathway inhibition. $^{36}$

Mitochondrial ATP-dependent K+ channel (MitoKATP) was found to inhibit the opening of mitochondrial permeability transition pore (mPTP) and thus suppress mitochondrial dysfunction. Moreover, MitoKATP could regulate redox balance and attenuate the generation of ROS and oxidative damages. A study by Shu et al also demonstrated that the activation of MitoKATP was critical for PHC post-conditioning-exerted effect on redox status, MPTP opening, apoptosis, inflammation, brain infarction and edema, and deficit of neurological function in $\mathrm{CI} / \mathrm{R}$ rats (Figure 5). ${ }^{37}$

As for the application of PHC in clinics, Wang et al found that administration of PHC to patients undergoing cardiopulmonary resuscitation can effectively improve cerebral perfusion pressure, lower intracranial pressure, reduce cerebral edema and inflammation, and eventually improve neurological functions. ${ }^{38}$ The mechanism is complex and not only involves inhibition of calcium influx but also effectively improves cell tolerance to ischemia and hypoxia, maintain lysosomal and mitochondrial activity, and reduces the level of arachidonic acid in the body. Moreover, PHC can effectively penetrate the blood-brain barrier, has anticholinergic effects on the central nervous system, and effectively inhibits $\mathrm{NF}-\kappa \mathrm{B}$ protein activity.

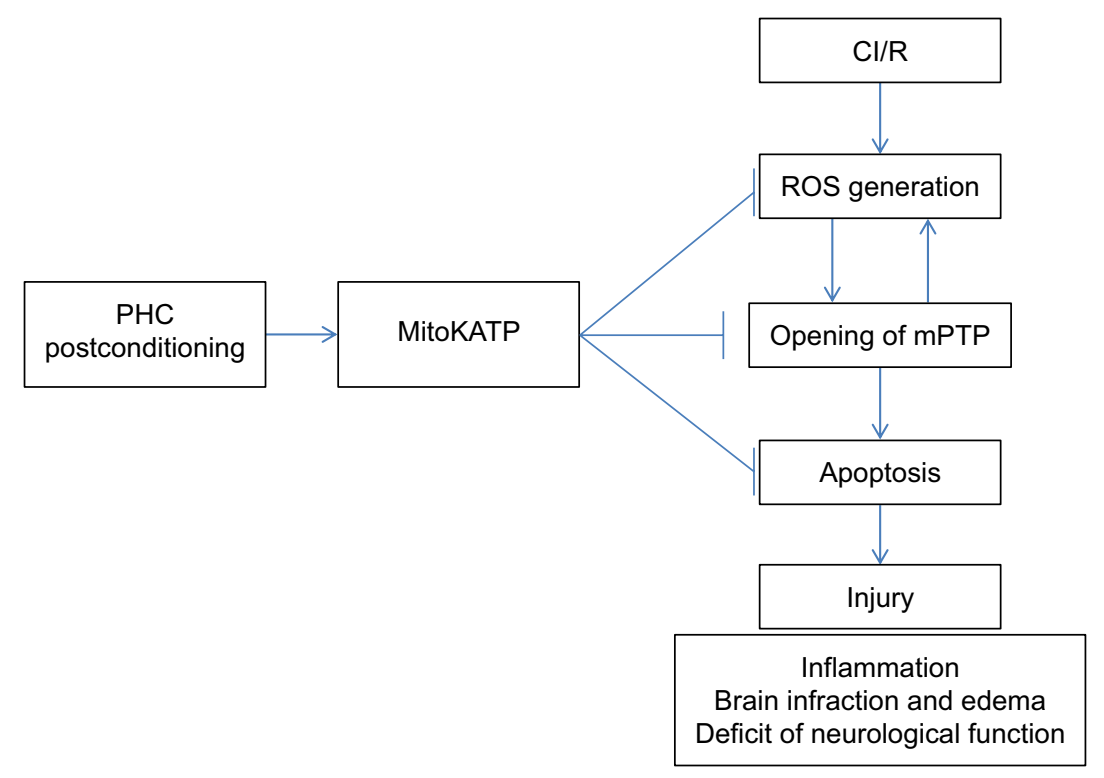

Figure $\mathbf{5}$ Mechanism of neuroprotective effect of $\mathrm{PHC}$ post-conditioning against I/R injury.

Abbreviations: $\mathrm{Cl} / \mathrm{R}$, cerebral ischemia/reperfusion; MitoKATP, mitochondrial ATP-dependent $\mathrm{K}+$ channel; mPTP, mitochondrial permeability transition pore; PHC, penehyclidine hydrochloride. 


\section{Application of $\mathrm{PHC}$ in renal protection}

Renal $\mathrm{I} / \mathrm{R}$ injury is a major cause of acute kidney failure via mechanisms that involve oxidative stress, inflammation, and apoptosis. A study by Wang et al showed that PHC treatment significantly attenuated renal dysfunction and histologic damage caused by I/R injury. PHC protected rat kidneys from I/R injury by attenuating oxidative stress, inflammatory response, and apoptosis. ${ }^{39}$ These mechanisms are similar with the abovementioned mechanisms.

Acute kidney injury (AKI) is one of the most severe complications of rhabdomyolysis (RM). Nrf2 is a master transcriptional regulator of the basal and inducible expressions of a battery of defensive genes encoding detoxifying enzymes and antioxidant proteins, including HO-1. A study by Zhao et al showed that PHC pretreatment ameliorated RM-induced AKI by promoting the Nrf2/HO-1 pathway in renal tissues, thus decreasing the accumulation of myoglobin in the kidney and alleviating oxidative stress. They also found that PHC pretreatment decreased the renal cell apoptosis rate by inhibiting endoplasmic reticulum stress and down-regulating glucose-regulated protein 78 and caspase-12 expression in renal tissues in rats. ${ }^{40}$

\section{Application of PHC in gastrointestinal diseases and intestinal mucosa}

There are many cholinergic receptors in the glands and smooth muscles of the digestive tract. PHC inhibits gastric acid secretion by blocking M receptors. PHC can also relieve gastrointestinal smooth muscle spasms, so it can be used in the treatment of gastrointestinal colic, biliary colic, and renal colic.

Limb ischemia-reperfusion (LIR) injury can not only lead to damage of the limb itself and other organs such as the heart, lungs, brain, and small intestines, but may also further trigger a systemic inflammatory response and multiple organ dysfunctions mainly induced by intestinal dysfunction and structural damage. A study by Zhang et al found that PHC post-conditioning can improve small intestinal mucosal injury induced by lower LIR. It may also reduce the permeability of the small intestines after LIR. Its protection mechanisms may be related to inhibiting oxygen free radicals and inflammatory cytokines in organ damage. ${ }^{41}$

In a clinical study by Sun et al on patients undergoing cardiopulmonary bypass, they found that PHC preserves intestinal barrier function integrity, attenuates endotoxemia, and inhibits the systemic inflammatory response in patients undergoing cardiopulmonary bypass, possibly by improving intestinal microcirculation and depressing the stress response. $^{42}$

\section{Application of PHC in septic shock}

The essence of shock is insufficient in microcirculation perfusion, ischemia, and anoxia in the metabolism of tissue cells. Septic shock is a typical type of distributed shock. Its clinical features are 1) infective foci, 2) hypotension, and 3 ) a systemic inflammatory response.

In addition to conventional volume resuscitation and active anti-infection, the use of vasoactive drugs is also an important treatment measures for septic shock. ${ }^{6}$ Anisodamine, a classical anticholinergic drug used in septic shock, can dilate the arterioles and microvasculature, improve microcirculation, protect cell membranes and subcellular structure membranes, increase tolerance to hypoxia, and reduce the mortality of septic shock. However, because anisodamine has no selectivity to $\mathrm{M}$ receptors, it may cause arrhythmias in situations of severe hypoxia or a very fast heart rate.

PHC does not accelerate heart rate, nor does it inhibit intestinal peristalsis. It is thus significantly superior to anisodamine in the treatment of septic shock. A large dose of PHC directly acts on vascular smooth muscles, relieves small vasospasms, reduces peripheral vascular resistance, improves microcirculation, and increases tissue perfusion. PHC can improve the tolerance of cells to ischemia and hypoxia, stabilize the subcellular structure of lysosomes and mitochondria, reduce the release of lysosomes, and inhibit the production of arachidonic acid metabolites and the formation of shock factors. ${ }^{25-26}$ However, it is necessary to increase the dose of PHC in the treatment of shock. The dosage is $0.04 \mathrm{mg} / \mathrm{kg}, \mathrm{q} 12 \mathrm{~h}$. After blood pressure returns to a normal range in 12 hours, the dosage reduces to once a day. The side effects need to be further studied, simultaneously with studies of PHC via intramuscular injection.

\section{Application of PHC in central sedation}

The postsynaptic membranes in the brain mainly contain $\mathrm{M}_{1}$ receptors and are mainly distributed in the cerebral cortex, striatum and brain stem reticular uplink activation system. Our results showed that PHC could induce central sedation through the following three mechanisms: 1) blocking the central $\mathrm{M}_{1}$ receptor, inhibiting arousal and its ether structure, and entering the blood-brain barrier easily; 2) inhibiting learning and memory activity, thus regulating the release of other inhibitory neurotransmitters in the central nervous system; and 3) inhibiting movement and weakening the excitability of the extrapyramidal system. The strong central anti- $\mathrm{M}_{1}$ receptor of $\mathrm{PHC}$ inhibits arousal, which makes it have a certain central sedative effect. 


\section{Other effects of PHC}

$\mathrm{PHC}$ can reduce peripheral resistance, regulate autonomic nerve and stress responses, and has a protective effect on liver injury of cardiopulmonary bypass in rats ${ }^{43}$ the effect is more obvious at a high dose. Classical anticholinergic drugs can be used in drug treatment. The central anticholinergic effect of $\mathrm{PHC}$ is stronger than that of classical anticholinergic drugs, and it has a central sedative effect which may be related to the curative effect of detoxification.

\section{Conclusion}

PHC has beneficial pharmacological actions, few side effects, and protective effects on multiple organs, indicating that it has an extensive potential clinical application value. Further study on its application for organ protection is warranted.

\section{Acknowledgment}

This work was supported by National Nature Science Foundation of China (grant number 81471902), Beijing Municipal Administration of Hospitals Clinical Medicine Development of Special Funding Support (code: ZYLX201810).

\section{Disclosure}

The authors report no conflicts of interest in this work.

\section{References}

1. Han XY, Liu H, Liu CH, et al. Synthesis of the optical isomers of a new anticholinergic drug, penehyclidine hydrochloride (8018). Bioorg Med Chem Lett. 2005;15(8):1979-1982.

2. Wang YA, Zhou WX, Li JX, et al. Anticonvulsant effects of phencynonate hydrochloride and other anticholinergic drugs in soman poisoning: neurochemical mechanisms. Life Sci. 2005;78(2):210-223.

3. Xiao HT, Liao Z, Zj M. Progress in pharmacokinetics of penehyclidine hydrochloride. Chin J New Drugs. 2009;18:887-890.

4. Shen W, Gan J, Xu S, Jiang G, Wu H. Penehyclidine hydrochloride attenuates LPS-induced acute lung injury involvement of NF-kappaB pathway. Pharmacol Res. 2009;60(4):296-302.

5. Lin D, Ma J, Xue Y, Wang Z. Penehyclidine Hydrochloride Preconditioning Provides Cardioprotection in a Rat Model of Myocardial Ischemia/Reperfusion Injury. PLoS One. 2015;10(12):e0138051.

6. Zhan J, Wang Y, Wang C, Li J, Zhang Z, Jia B. Protective effects of penehyclidine hydrochloride on septic mice and its mechanism. Shock. 2007; 28(6):727-732.

7. Eddleston M. Patterns and problems of deliberate self-poisoning in the developing world. Q JMed. 2000;93:715-731.

8. Van der Hoek W, Konradsen F, Athukorala K, Wanigadewa T. Pesticide poisoning: a major health problem in Sri Lanka. Soc Sci Med. 1998; 46(4-5):495-504.

9. Hong-Jing WU, Bin-Cheng LOU, Dai-Kun H. Clincal study of penehyclidime hydrochloride in the treatment of organic phosphorus poisoning. J Peking Univ Rs Ity. 2001;33(No. 1)2-3.

10. Wenjie T, Xiaoming Q, Xuehao W, et al. Treatment of severe organophosphorus poisoning with penehyclidine hydrochloride. J Clin Anesthesiol. 2005;21(No. 6)2-3.
11. Cui J, Li CS, He XH, Song YG. Protective effects of penehyclidine hydrochloride on acute lung injury caused by severe dichlorvos poisoning in swine. Chin Med J. 2013;126(24):4764-4770.

12. Yu LQ, Zheng XQ. Clinical study of effect of penehyclidine hydrochloride and atropine sequential therapy in the treatment of severe acute organophosphorus pesticide poisoning. Zhongguo Wei Zhong Bing Ji Jiu Yi Xue. 2012;24(6):349-351.

13. Liu XB, Pan S, Yang XG, et al. Effect of penehyclidine hydrochloride on heart rate variability in hysteroscopy. Exp Ther Med. 2015;10(1): 181-186.

14. Wang J, Ren Y, Zhu Y, et al. Effect of penehyclidine hydrochloride on the incidence of intra-operative awareness in Chinese patients undergoing breast cancer surgery during general anaesthesia. Anaesthesia. 2013;68(2):136-141.

15. Wessler I, Kirkpatrick CJ. Acetylcholine beyond neurons: the nonneuronal cholinergic system in humans. Br J Pharmacol. 2008;154(8): 1558-1571.

16. Myers AC, Undem BJ. Muscarinic receptor regulation of synaptic transmission in airway parasympathetic ganglia. Am J Physiol. 1996; 270(4 Pt 1):L630-L636.

17. Fryer AD, Elbon CL, Kim AL, Xiao HQ, Levey AI, Jacoby DB. Cultures of airway parasympathetic nerves express functional M2 muscarinic receptors. Am J Respir Cell Mol Biol. 1996;15(6):716-725.

18. Fisher JT, Vincent SG, Gomeza J, Yamada M, Wess J. Loss of vagally mediated bradycardia and bronchoconstriction in mice lacking M2 or M3 muscarinic acetylcholine receptors. FASEB J. 2004;18(6):711-713.

19. Ramnarine SI, Haddad EB, Khawaja AM, Mak JC, Rogers DF. On muscarinic control of neurogenic mucus secretion in ferret trachea. J Physiol. 1996;494(Pt 2):577-586.

20. Buels KS, Fryer AD. Muscarinic receptor antagonists: effects on pulmonary function. Handb Exp Pharmacol. 2012;(208):317-341.

21. Xiao HT, Liao Z, Tong RS. Penehyclidine hydrochloride: a potential drug for treating COPD by attenuating Toll-like receptors. Drug Des Devel Ther. 2012;6:317-322.

22. Li BQ, Sun HC, Nie SN, Shao DB, Liu HM, Qian XM. Effect of penehyclidine hydrochloride on patients with acute lung injury and its mechanisms. Chin J Traumatol. 2010;13(6):329-335.

23. Wu XJ, Xia ZY, Wang LL, et al. Effects of penehyclidine hydrochloride on pulmonary contusion from blunt chest trauma in rats. Injury. 2012; 43(2):232-236

24. Wang LL, Zhan LY, Wu XJ, Xia ZY. Effects of penehyclidine hydrochloride on apoptosis of lung tissues in rats with traumatic acute lung injury. Chin J Traumatol. 2010;13(1):15-19.

25. Zhan J, Liu Y, Zhang Z, Chen C, Chen K, Wang Y. Effect of penehyclidine hydrochloride on expressions of MAPK in mice with CLP-induced acute lung injury. Mol Biol Rep. 2011;38(3):1909-1914.

26. Zhan J, Xiao F, Zhang ZZ, et al. Effect of penehyclidine hydrochloride on $\beta$-arrestin-1 expression in lipopolysaccharide-induced human pulmonary microvascular endothelial cells. Braz J Med Biol Res. 2013; 46(12):1040-1046.

27. Wu GM, Mou M, Mo LQ, et al. Penehyclidine hydrochloride postconditioning on lipopolysaccharide-induced acute lung injury by inhibition of inflammatory factors in a rodent model. J Surg Res. 2015;195(1): 219-227.

28. Hoover DB. Cholinergic modulation of the immune system presents new approaches for treating inflammation. Pharmacol Ther. 2017; 179:1-16.

29. Wang Z, Lin D, Zhang L, Liu W, Tan H, Ma J. Penehyclidine hydrochloride prevents anoxia/reoxygenation injury and induces $\mathrm{H} 9 \mathrm{c} 2 \mathrm{car}$ diomyocyte apoptosis via a mitochondrial pathway. Eur J Pharmacol. 2017;797:115-123.

30. Tan H, Lin D, Wang Z, Yang Y, Ma J. Cardioprotective time-window of Penehyclidine hydrochloride postconditioning: A rat study. Eur $J$ Pharmacol. 2017;812(812):48-56.

31. Tan H, Chen L, Ma J. Penehyclidine hydrochloride post-conditioning reduces ischemia/reperfusion-induced cardiomyocyte apoptosis in rats. Exp Ther Med. 2017;14(5):4272-4278. 
32. Lin D, Cui B, Ren J, Ma J. Regulation of VDAC1 contributes to the cardioprotective effects of penehyclidine hydrochloride during myocardial ischemia/reperfusion. Exp Cell Res. 2018;367(2):257-263.

33. Yang Y, Zhao L, Ma J. Penehyclidine hydrochloride preconditioning provides cardiac protection in a rat model of myocardial ischemia/ reperfusion injury via the mechanism of mitochondrial dynamics mechanism. Eur J Pharmacol. 2017;813:130-139.

34. Yu C, Wang J. Neuroprotective effect of penehyclidine hydrochloride on focal cerebral ischemia-reperfusion injury. Neural Regen Res. 2013; 8(7):622-632.

35. Shang Y, Gu PF, Shang Y, Li Y. Penehyclidine hydrochloride inhibits glutamate release and related research in global brain ischemia/ reperfusion rats. Zhongguo Ying Yong Sheng Li Xue Za Zhi. 2011;27(3): 353-356.

36. Shu Y, Yang Y, Zhang P. Neuroprotective effects of penehyclidine hydrochloride against cerebral ischemia/reperfusion injury in mice. Brain Res Bull. 2016;121:115-123.

37. Shu Y, Li Z, Han B. Penehyclidine hydrochloride postconditioning ameliorates cerebral ischemia-reperfusion injury: critical role of mitochondrial ATP sensitive potassium channel. J Biol Regul Homeost Agents. 2016;30(1):41-53.
38. Wang D, Jiang Q, Du X. Protective effects of scopolamine and penehyclidine hydrochloride on acute cerebral ischemia-reperfusion injury after cardiopulmonary resuscitation and effects on cytokines. Exp Ther Med. 2018;15(2):2027-2031.

39. Wang YP, Li G, Ma LL, et al. Penehyclidine hydrochloride ameliorates renal ischemia-reperfusion injury in rats. J Surg Res. 2014; 186(1):390-397.

40. Zhao W, Huang X, Zhang L, et al. Penehyclidine Hydrochloride Pretreatment Ameliorates Rhabdomyolysis-Induced AKI by Activating the Nrf2/HO-1 Pathway and Alleviating [corrected] Endoplasmic Reticulum Stress in Rats. PLoS One. 2016;11(3):e0151158.

41. Zhang Y, Leng YF, Xue X, Zhang Y, Wang T, Kang YQ. Effects of penehyclidine hydrochloride in small intestinal damage caused by limb ischemia-reperfusion. World J Gastroenterol. 2011;17(2):254.

42. Sun YJ, Song DD, Diao YG, Zhou J, Zhang TZ. Penehyclidine hydrochloride preserves the intestinal barrier function in patients undergoing cardiopulmonary bypass. J Thorac Cardiovasc Surg. 2013;146(1): 179-185.

43. Cai DS, Jin BB, Pei L, Jin Z. Protective effects of penehyclidine hydrochloride on liver injury in a rat cardiopulmonary bypass model. Eur $J$ Anaesthesiol. 2010;27(9):824-828.

\section{Publish your work in this journal}

Drug Design, Development and Therapy is an international, peerreviewed open-access journal that spans the spectrum of drug design and development through to clinical applications. Clinical outcomes, patient safety, and programs for the development and effective, safe, and sustained use of medicines are the features of the journal, which has also been accepted for indexing on PubMed Central. The manuscript management system is completely online and includes a very quick and fair peer-review system, which is all easy to use. Visit http://www.dovepress.com/testimonials.php to read real quotes from published authors.

Submit your manuscript here: http://www.dovepress.com/drug-design-development-and-therapy-journal 